\title{
COMMENTARY
}

\section{Glycemic variability is complex - is glucose complexity variable?}

\author{
Roosmarijn TM van Hooijdonk*1, Ameen Abu-Hanna² and Marcus J Schultz',3
}

See related research by Brunner et al., http://ccforum.com/content/16/5/R175

\begin{abstract}
Observational studies show an independent association between increased glycemic variability and higher mortality in critically ill patients. Minimization of glycemic variability is therefore suggested as a new target of glycemic control, which may require very frequent or almost continuous monitoring of glucose levels. Brunner and colleagues show the use of realtime subcutaneous continuous glucose monitoring does not decrease glycemic variability. Continuous glucose monitoring, however, may reveal changes in glucose complexity, which may be of interest since both increased and decreased glucose complexity is associated with higher mortality in the critically ill.
\end{abstract}

In the previous issue of Critical Care Brunner and colleagues report on the results of a post-hoc analysis [1] of two previously published randomized controlled trials evaluating real-time subcutaneous continuous glucose monitoring (CGM) in critically ill patients $[2,3]$. Their main findings are that glycemic control guided by realtime CGM does not significantly reduce glycemic variability (GV) and that both increased and decreased glucose complexity is significantly associated with ICU survival and with the presence of diabetes.

There is an independent association between increased GV and higher mortality in ICU patients [4,5]. GV depends on endogenous factors (for example, severity of illness) but also on exogenous factors (for example, inappropriate glucose measurement intervals and improper insulin adjustments). Minimization of GV is suggested as a new target of glycemic control [6], which may require very frequent or almost continuous

\footnotetext{
*Correspondence: r.t.vanhooijdonk@amc.uva.nl

'Department of Intensive Care, G3-227, Academic Medical Center, University of Amsterdam, Meibergdreef 9, 1105 DD Amsterdam, the Netherlands

Full list of author information is available at the end of the article
}

monitoring of glucose levels. However, a secondary analysis of the first two Leuven studies shows that strict glycemic control, which includes frequent monitoring of the blood glucose level, does not decrease GV [7]. The present study shows that strict glycemic control using almost continuous monitoring also does not decrease GV [1].

Therefore it is very difficult, if not impossible, to decrease GV. Are the nurses in Brunner and colleagues' ICU already performing strict glycemic control so well that GV simply cannot be further decreased? Notably, the standard deviation - one of the measures of GV used by the present analysis - is already very low in the control group compared with values reported in previous studies. Nurses could also poorly or only sporadically respond to the real-time CGM results with alterations in insulin infusion, thereby losing any potential for real-time CGM to further decrease GV. We should also not forget that the present study uses subcutaneous glucose levels and not blood glucose levels for calculation of indicators of GV. Subcutaneous GV may simply not be the same as blood GV. Finally, we must keep in mind that the sample frequency per se may affect the calculation of indicators of GV. Indeed, indicators of GV may not only truly reflect $\mathrm{GV}$, but may also depend on the number of measurements per time unit used for its calculation [8]. Brunner and colleagues actually confirm this dependency in their analysis of the impact of the method of glucose determination on indicators of GV [1].

Less well known is that loss of glucose complexity is also associated with higher mortality of critically ill patients. Complex biological systems are characterized by a highly complex output, and one of the first symptoms of disease is decomplexification $[9,10]$. Well-known examples include decreased intrauterine heart rate complexity with fetal stress, and decreased heart rate and temperature complexity with severe infection. Complexity, in contrast to variability, depends on endogenous factors, and not on exogenous factors. Interestingly, progressive loss of glucose complexity is found from health through the metabolic syndrome to type II diabetes [11-14]. The results of the present study are in 


[3]
INCREASED

line with those findings, at least to some extent. They also echo the results from a previous investigation showing that loss of glucose complexity is associated with higher mortality [15]. The finding that increased glucose complexity is also associated with higher mortality, however, is new. Therefore, next to hyperglycemia, hypoglycemia and GV, glucose complexity should be seen as one new domain of glycemia (Figure 1), although glucose complexity cannot be changed by titration of insulin.

As we speak, several CGM systems are being developed and clinically tested in critically ill patients. These systems all have the potential to improve performance and safety of insulin titration in the ICU. They may also improve our insights into insulin resistance and help us to better understand the impact of GV on outcome. The present study not only shows that GV does not improve with the use of CGM per se, but also suggests that we need to develop better measures of GV, independent of the sample frequency. Finally, CGM systems allow us to determine and follow changes in glucose complexity. This allows one to inspect whether glucose complexity increases (from decreased complexity) or decreases (from increased complexity) in individual patients, and to determine whether these changes follow changes in insulin resistance over time. If this indeed is the case, then CGM could even help us in decisions to start or stop strict glycemic control in individual patients, thereby preventing side effects of insulin infusion.

\section{Abbreviations}

CGM, continuous glucose monitoring; GV, glycemic variability.

\section{Competing interests}

MJS has performed consulting work for Medtronic Inc., GlySyre Ltd, Roche Diagnostics, Edwards Life Sciences, and Optiscan Biomedical, and has received research support from Medtronic Inc. and Optiscan Biomedical. RTMvH has performed consulting work for Medtronic Inc., GlySyre Ltd, and has received research support from Medtronic Inc. and Optiscan Biomedical. AAH declares that he has no competing interests.

\section{Author details}

'Department of Intensive Care, G3-227, Academic Medical Center, University of Amsterdam, Meibergdreef 9, 1105 DD Amsterdam, the Netherlands. 2Department of Medical Informatics, Academic Medical Center, University of Amsterdam, Meibergdreef 9, 1105 DD Amsterdam, the Netherlands. 3 Laboratory of Experimental Intensive Care and Anesthesiology, Academic Medical Center, University of Amsterdam, Meibergdreef 9, 1105 DD Amsterdam, the Netherlands.

Published: 21 November 2012

\section{References}

1. Brunner R, Adelsmayr G, Herkner H, Madl C, Holzinger U: Glycemic variability and glucose complexity in critically ill patients: a retrospective analysis of continuous glucose monitoring data. Crit Care 2012, 16:R175.

2. Holzinger $U$, Warszawska J, Kitzberger R, Herkner H, Metnitz PG, Madl C: Impact of shock requiring norepinephrine on the accuracy and reliability of subcutaneous continuous glucose monitoring. Intensive Care Med 2009 35:1383-1389.

3. Holzinger U, Warszawska J, Kitzberger R, Wewalka M, Miehsler W, Herkner H, Madl C: Real-time continuous glucose monitoring in critically ill patients: a prospective randomized trial. Diabetes Care 2010, 33:467-472.

4. Krinsley JS: Glycemic variability: a strong independent predictor of mortality in critically ill patients. Crit Care Med 2008, 36:3008-3013.

5. Hermanides J, Vriesendorp TM, Bosman RJ, Zandstra DF, Hoekstra JB, Devries $\mathrm{JH}$ : Glucose variability is associated with intensive care unit mortality. Crit 
Care Med 2010, 38:838-842

6. Vincent JL: Blood glucose control in 2010: 110 to $150 \mathrm{mg} / \mathrm{dl}$ and minimal variability. Crit Care Med 2010, 38:993-995.

7. Meyfroidt G, Keenan DM, Wang X, Wouters PJ, Veldhuis JD, Van den Berghe G: Dynamic characteristics of blood glucose time series during the course of critical illness: effects of intensive insulin therapy and relative association with mortality. Crit Care Med 2010, 38:1021-1029.

8. Eslami S, Taherzadeh Z, Schultz MJ, Abu-Hanna A: Glucose variability measures and their effect on mortality: a systematic review. Intensive Care Med 2011, 37:583-593.

9. Goldberger AL, Amaral LA, Hausdorff JM, Ivanov P, Peng CK, Stanley HE: Fractal dynamics in physiology: alterations with disease and aging. Proc Natl Acad Sci U S A 2002, 99(Suppl 1):2466-2472

10. Goldstein B, Fiser DH, Kelly MM, Mickelsen D, Ruttimann U, Pollack MM: Decomplexification in critical illness and injury: relationship between heart rate variability, severity of illness, and outcome. Crit Care Med 1998, 26:352-357.

11. Churruca J, Vigil L, Luna E, Ruiz-Galiana J, Varela M: The route to diabetes: loss of complexity in the glycemic profile from health through the metabolic syndrome to type 2 diabetes. Diabetes Metab Syndr Obes 2008, 1:3-11
12. Ogata H, Tokuyama K, Nagasaka S, Ando A, Kusaka I, Sato N, Goto A, Ishibashi S, Kiyono K, Struzik ZR, Yamamoto Y: Long-range negative correlation of glucose dynamics in humans and its breakdown in diabetes mellitus. Am J Physiol Regul Integr Comp Physiol 2006, 291:R1638-R1643.

13. Ogata H, Tokuyama K, Nagasaka S, Tsuchita T, Kusaka I, Ishibashi S, Suzuki H, Yamada N, Hamano K, Kiyono K, Struzik ZR, Yamamoto Y: The lack of longrange negative correlations in glucose dynamics is associated with worse glucose control in patients with diabetes mellitus. Metabolism 2012, 61:1041-1050.

14. Yamamoto N, Kubo Y, Ishizawa K, Kim G, Moriya T, Yamanouchi T, Otsuka K: Detrended fluctuation analysis is considered to be useful as a new indicator for short-term glucose complexity. Diabetes Technol Ther 2010, 12:775-783.

15. Lundelin K, Vigil L, Bua S, Gomez-Mestre I, Honrubia T, Varela M: Differences in complexity of glycemic profile in survivors and nonsurvivors in an intensive care unit: a pilot study. Crit Care Med 2010, 38:849-854.

doi:10.1186/cc11834

Cite this article as: van Hooijdonk RTM, et al.: Glycemic variability is complex - is glucose complexity variable? Critical Care 2012, 16:178 